\title{
Performance investigation of multiple-tube ground heat exchangers for ground-source heat pump
}

\author{
Jalaluddin ${ }^{1, *}$, Akio Miyara ${ }^{2}$ \\ ${ }^{1}$ Department of Mechanical Engineering, Hasanuddin University, Makassar, Indonesia \\ ${ }^{2}$ Department of Mechanical Engineering, Saga University, Saga-shi, Japan
}

Email address:

jalaluddin_had@yahoo.com (Jalaluddin), miyara@me.saga-u.ac.jp (A. Miyara)

\section{To cite this article:}

Jalaluddin, Akio Miyara. Performance Investigation of Multiple-Tube Ground Heat Exchangers for Ground-Source Heat Pump. American Journal of Energy Engineering. Vol. 2, No. 5, 2014, pp. 103-107. doi: 10.11648/j.ajee.20140205.11

\begin{abstract}
The present study aims to investigate the performance of multiple-tube ground heat exchangers (GHEs). The multiple-tube GHEs with a number of pipes installed inside the borehole were simulated. Thermal interferences between the pipes and performance of multiple-tube GHEs are discussed. Increasing the number of inlet tube in the borehole increases the contact surface area and then leads to increase of heat exchange with the ground. However, ineffective of heat exchange in the outlet tube caused by thermal interferences from the inlet tube reduces the heat exchange rate for the GHEs. The GHE performances increase of $9.1 \%$ for three-tube, of $13.6 \%$ for four-tube, and of $20.1 \%$ for multi-tube compared with that of the U-tube. The four-tube and multi-tube GHEs which consist of four pipes as heat exchange pipes where the multi-tube GHE provides better performance than that of the four-tube GHE. This fact indicates that thermal interferences between the pipes affect the performance. Thermal interferences between the pipes should be considered.
\end{abstract}

Keywords: Heat Exchange Rate, Thermal Interferences, Multiple-Tube GHEs

\section{Introduction}

The geothermal energy source is categorized based on ASHRAE [1] for using in high-temperature electric power production; $>150{ }^{\circ} \mathrm{C}$, intermediate and low-temperature direct-use applications; $<150{ }^{\circ} \mathrm{C}$, and Ground-source heat pump (GSHP) system applications; generally $<32{ }^{\circ} \mathrm{C}$. The GSHP system has been widely used in engineering application for space heating and cooling. The GHEs used in the GSHP system are installed in either horizontal trenches or vertical boreholes. Short-term and long-term performances are important issues of the GSHP system. Both the short-term and long-term behavior of ground loop heat exchangers is critical to the design and energy analysis of ground-source heat pump systems [2]. Short-term analysis is required for detailed building energy analysis and the design of hybrid GSHP system [3, 4]. It helps to understand the effects of short duration peak loads on the ground response [5-9] and to establish the running control strategies for alternative operation modes in short time scales of operation such as for cooling, heating, and hot water heating according to different requirements [10]. The GHEs used in the GSHP system are installed in either horizontal trenches or vertical boreholes. Temperature distributions, energy and exergy performances for two different horizontal GHEs [11, 12] and for three

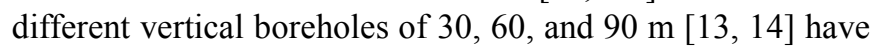
been reported.

Several factors such as local conditions, ground heat exchanger (GHE) parameters, and operation conditions contribute significantly to the thermal performance of the GHE that used in the GSHP system to exchange heat with the ground. Analyzing the GHE performance in those conditions is needed to provide an accurate prediction of the performance in the GSHP system design. A number of studies have investigated the GHE performance in various backfilled materials, concrete pile foundations, and configuration shapes [15-18]. Heat exchange rate of the GHE was also evaluated by Jun et al. [19] with considering the effect of running time, shank spacing, depth of borehole, velocity in the pipe, thermal conductivity of grout, inlet temperature and soil type.

Experimental study of thermal performance of three types of GHEs including U-tube, double-tube, and multi-tube types installed in a steel pile foundation with $20 \mathrm{~m}$ of depth has been done [20]. The heat exchange rates of the GHEs in 24 hours of continuous operation with flow rates of 2,4 , and $81 / \mathrm{min}$ and the effect of increasing the flow rate have been discussed. The performance of the GHEs has been also investigated in different operation modes [21]. Operating the GHEs with 
different operation mode shows the different characteristic in their heat exchange rates.

This work investigates thermal interference and performance of multiple-tube ground heat exchangers (GHEs). The multiple-tube GHEs with a number of pipes installed inside the borehole were simulated in order to investigate the thermal interferences between the tubes and their performances.

\section{Numerical Method}

\subsection{GHE Models}

Three-dimensional unsteady-state models for multiple tubes of GHEs were built and simulated by using a commercial CFD code, FLUENT. Steel pipes, which are used as foundation pile for houses, were buried in the ground and used as boreholes for the GHEs. Multiple-tube GHEs including U-tube, multi-tube, three-tube, four-tube types where a number of pipes installed inside the boreholes at $20 \mathrm{~m}$ depth were simulated in order to investigate the thermal interferences between the tubes and their performances. The multiple tubes were inserted in the steel pile, and the gaps between the steel pile and tubes were grouted with silica-sand. In addition, the multi-tube consists of a central insulated-pipe as the outlet tube and four pipes as the inlet tubes placed around the central pipe. The three-tube and four-tube types were built with installing three and four tubes inside the boreholes which consists of two inlet and one outlet tubes for the three tube type and three inlet and one outlet tubes for the four-tube type, respectively. For all the GHEs, polyethylene is
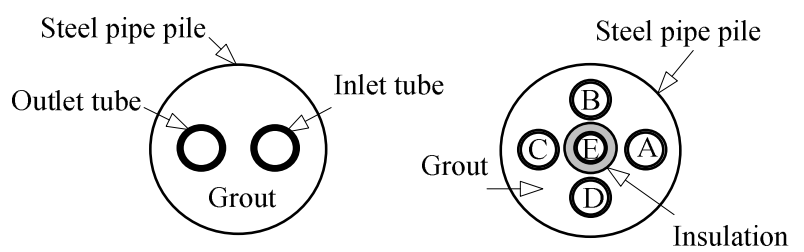

A, B, C, D : Inlet tubes

E: Outlet tube

used as a tube material.

The ground around the GHEs is modeled of $5 \mathrm{~m}$ in radius. Fig. 1 shows the horizontal cross-sections of the multiple tube types of GHE models. Three-dimensional hybrid mesh generation was applied in the GHE models. All the related geometric parameters and material thermal properties for the GHEs are listed in Table 1.

Table 1. Related geometric parameters and material thermal properties of the GHEs.

\begin{tabular}{lcc}
\hline Parameters & Value & Unit \\
\hline U-tube, Tri-tube and Four-tube & & \\
Inlet and outlet pipes of the multiple-tube & GHEs & (material: Polyethylene) \\
Outer diameter, $d_{o}$ & 0.033 & $\mathrm{~m}$ \\
Inner diameter, $d_{i}$ & 0.026 & $\mathrm{~m}$ \\
Thermal conductivity, $k_{P E}$ & 0.35 & $\mathrm{~W} /(\mathrm{m} \mathrm{K})$ \\
Multi-tube & & \\
Inlet pipes of the multi-tube (material: Polyethylene) & \\
Outer diameter, $d_{o}$ & 0.025 & $\mathrm{~m}$ \\
Inner diameter, $d_{i}$ & 0.02 & $\mathrm{~m}$ \\
Thermal conductivity, $k_{P V C}$ & 0.35 & $\mathrm{~W} /(\mathrm{m} \mathrm{K})$ \\
Outlet pipe of the multi-tube (material: Polyethylene) & \\
Outer diameter, $d_{o}$ & 0.02 & $\mathrm{~m}$ \\
Inner diameter, $d_{i}$ & 0.016 & $\mathrm{~m}$ \\
Thermal conductivity, $k_{P V C}$ & 0.35 & $\mathrm{~W} /(\mathrm{m} \mathrm{K})$ \\
Pile foundation of the multiple-tube GHEs (material: Steel) & \\
Outer diameter, $d_{o}$ & 0.1398 & $\mathrm{~m}$ \\
Inner diameter, $d_{i}$ & 0.1298 & $\mathrm{~m}$ \\
Thermal conductivity, $k_{\text {Steel }}$ & 54 & $\mathrm{~W} /(\mathrm{m} \mathrm{K})$ \\
Grout (material: Silica sand) & & \\
Thermal conductivity, $k_{\text {grout }}$ & 1.4 & $\mathrm{~W} /(\mathrm{m} \mathrm{K})$ \\
\hline
\end{tabular}

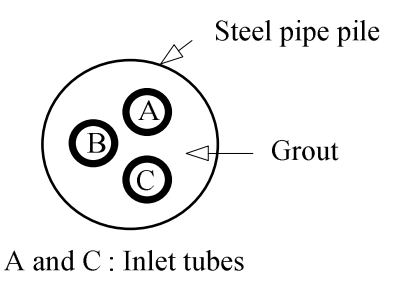

B : Outlet tube

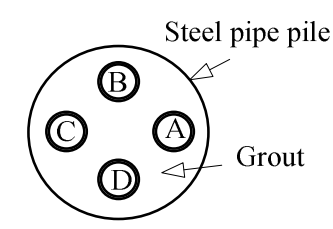

A, B, D : Inlet tubes

$\mathrm{C}$ : Outlet tube

U-tube

Multi-tube

Three-tube

Four-tube

Figure 1. The horizontal cross-sections of the multiple-tube GHEs.

\subsection{Boundary Conditions}

The ground profiles around the borehole consist of Clay, sand, and Sandy-clay. This ground profiles are typical for Saga city, Japan [21]. The ground properties can be estimated using the values for similar ground profiles in this simulation.

The thermal characteristic parameters of the ground are:

- Clay $\left(\rho=1700 \mathrm{~kg} / \mathrm{m}^{3}, k=1.2 \mathrm{~W} / \mathrm{m} \mathrm{K}, c=1800 \mathrm{~J} / \mathrm{kg} \mathrm{K}\right)$

- Sand $\left(\rho=1510 \mathrm{~kg} / \mathrm{m}^{3}, k=1.1 \mathrm{~W} / \mathrm{m} \mathrm{K}, c=1100 \mathrm{~J} / \mathrm{kg} \mathrm{K}\right)$

- Sandy-clay $\left(\rho=1960 \mathrm{~kg} / \mathrm{m}^{3}, k=2.1 \mathrm{~W} / \mathrm{m} \mathrm{K}, c=1200\right.$ $\mathrm{J} / \mathrm{kg} \mathrm{K}$ )

A constant and uniform temperature was applied to the top and bottom surfaces of the model. Variation of ground temperature near the surface due to ambient climate effect is negligible. Uniform initial ground temperature is assumed to be equal to the undisturbed ground temperature and constant of $17.7{ }^{\circ} \mathrm{C}$. This value is based on recorded data of local ground temperature at Saga city, Japan [20]. Inlet temperature and flow rate of circulated water are specified as boundary conditions. The inlet water temperature was set to be constant of $27{ }^{\circ} \mathrm{C}$. The flow rate of circulated water was set to $16 \mathrm{l} / \mathrm{min}$. For the GHE models that used more than one inlet pipe, this flow rate is the total flow rate of the inlet pipes. k-epsilon two equation turbulence models were applied in the FLUENT simulation set-up. Scaled residuals for turbulence models were monitored. 


\section{Heat Transfer Model}

Three-dimensional unsteady-state model used in simulation is:

$$
k\left(\frac{\partial T^{2}}{\partial x^{2}}+\frac{\partial T^{2}}{\partial y^{2}}+\frac{\partial T^{2}}{\partial z^{2}}\right)=\rho c \frac{\partial T}{\partial t}
$$

where $k$ is thermal conductivity $(\mathrm{W} / \mathrm{m} \mathrm{K}), T$ is temperature $(\mathrm{K})$, $\rho$ is density $\left(\mathrm{kg} / \mathrm{m}^{3}\right), c$ is specific heat $(\mathrm{J} / \mathrm{kg} \mathrm{K}), \mathrm{t}$ is time and $\mathrm{z}$ is depth.

Temperature variation distribution of circulated water is simulated and the thermal performances of the GHEs were investigated by calculating their heat exchange rates through the water flow. The heat exchange rate is calculated by the following equation

$$
Q=\dot{m} c_{p} \Delta T
$$

where $\dot{m}$ is flow rate, $c_{p}$ is specific heat, and $\Delta \mathrm{T}$ is the temperature difference between the inlet and outlet tubes of circulated water.

The heat exchange rate per unit borehole depth is defined as the following equation and it is used to express the performance of each GHEs.

$$
\bar{Q}=Q / L
$$

where $L$ is the depth of each GHE.

\section{Results and Discussion}

\subsection{Thermal Interferences Effect}

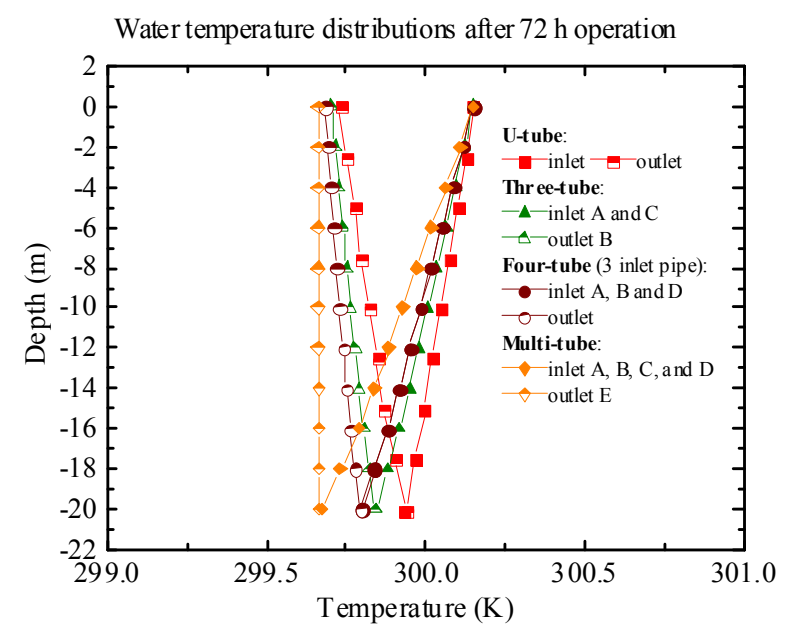

Figure 2. Water temperature distributions of multiple-tube GHEs.

Figure 2 shows the water temperature distribution of the multiple-tube GHEs after $72 \mathrm{~h}$ operation. The temperatures of water are measured at the central point of the tubes. Water temperature distributions decrease in the inlet and outlet tubes of the U-tube GHE. In the three-tube GHE, the water temperature distribution in the inlet tube decreases more than that of the U-tube but the water temperature changes in the outlet tube is smaller than that of the U-tube. It indicates that effectiveness of the outlet tube decreases due to the thermal interferences from the two inlet tubes. The cross-sectional temperature distributions at $10 \mathrm{~m}$ depth after $72 \mathrm{~h}$ operation are shown in Fig. 3. The thermal interferences between the inlet and outlet tubes can be seen from these figures. In comparison with the U-tube GHE, the outlet tube of the three-tube GHE is affected by thermal interferences more significant than that of the U-tube GHE as shown in Fig. 3 (b). This fact proves that the water temperature is slightly change caused by thermal interference from the inlet tubes. A similar characteristic of the water temperature distribution is found in the four-tube GHE. In the multi-tube GHE, the water temperature decrease in the inlet tube is largest among those of other GHEs. The thermal interferences from the inlet tubes to the outlet tube are prevented by insulation of the outlet tube and then, the water temperature stays almost constant in the outlet.

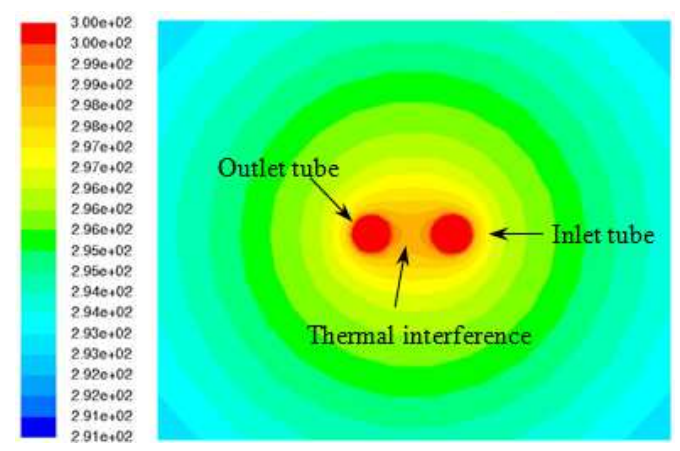

(a)U-tube

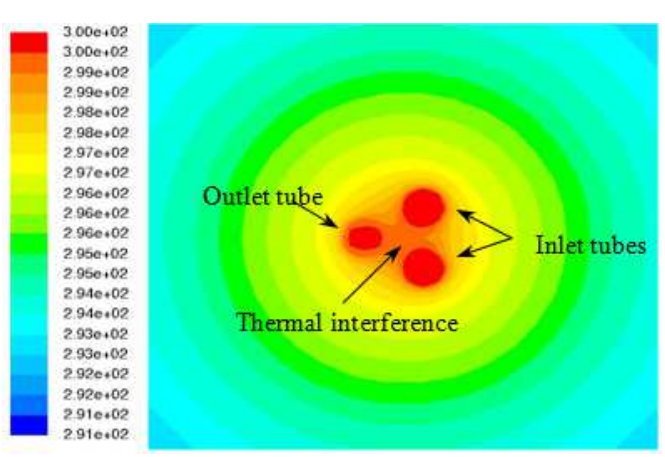

(b)Three-tube

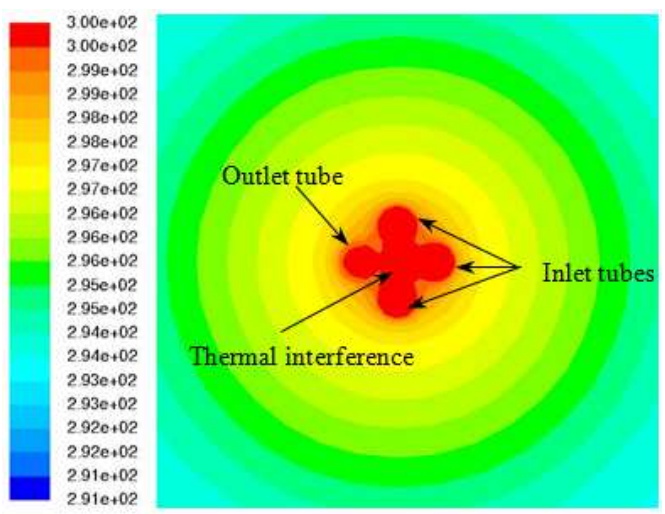

(c)Four-tube 


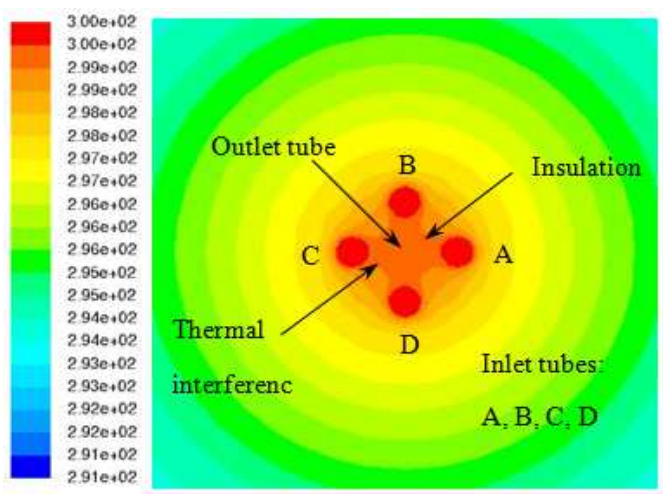

(d)Multi-tube

Figure 3. The cross-sectional temperature distributions at $10 \mathrm{~m}$ depth after 72 $h$ continuous operation.

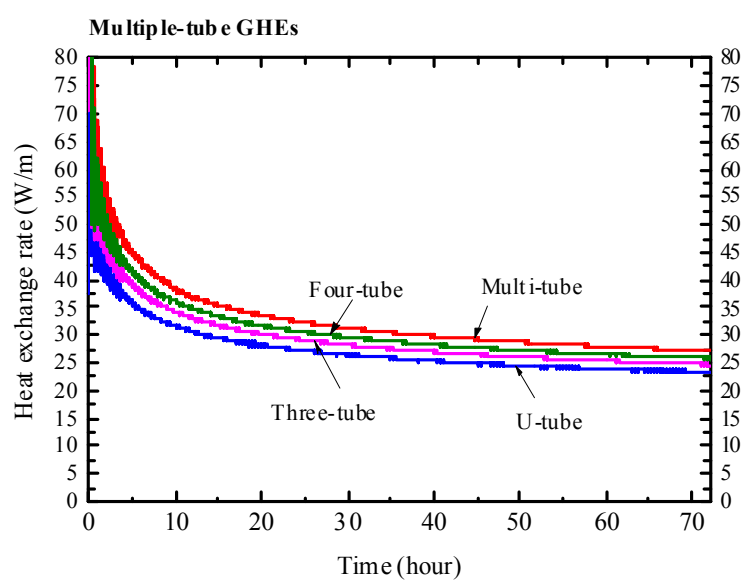

Figure 4. Heat exchange rates of multiple-tube GHEs

\subsection{Thermal Performances of the Multiple-Tube GHEs}

Figure 4 shows the heat exchange rates of the GHEs with operating time. In the three-tube and four-tube GHEs, increasing the number of inlet tubes increases the contact surface area and then leads to increase of heat exchange. However, ineffective of heat exchange in the outlet tube caused by thermal interferences from the inlet tubes reduces the heat exchange rates for the both GHEs. In the case of the multi-tube GHE, increasing the contact surface area and protecting thermal interference by insulation of the outlet tube contributes to the heat exchange rate. This result shows that installing a number of pipes inside the borehole does not increase the heat exchange rate of GHE linearly with increasing the contact surface area. Thermal interferences between the pipes should be considered. Effect of thermal interference between the tubes to the GHE thermal performance can be seen from the four-tube and multi-tube GHES which consist of four heat exchange pipes. The multi-tube GHE provides a better performance compared with that of in the four-tube GHE. It is due to insulation of outlet tube in the multi-tube GHE. This fact indicates that thermal interferences between the pipes affect the GHE performance. Average heat exchange rates of the multiple-tube GHEs after operating in $72 \mathrm{~h}$ are listed in Table 2. The GHE performances increase of $9.1 \%$ for three-tube, of
$13.6 \%$ for four-tube, and of $20.1 \%$ for multi-tube compared with that of the U-tube GHE.

Table 2. Heat exchange rates of the multiple-tube GHEs after operating in $72 \mathrm{~h}$.

\begin{tabular}{ll}
\hline Multiple-tube GHEs & $\begin{array}{l}\text { Average heat exchange rate in } \mathbf{7 2} \mathbf{~ h},\left(\bar{Q}_{72 h} / L\right) \\
(\mathbf{W} / \mathbf{m})\end{array}$ \\
\hline U-tube & 27.09 \\
Tri-tube & 29.55 \\
Four-tube & 30.77 \\
Multi-tube & 32.53 \\
\hline
\end{tabular}

\section{Conclusions}

The geothermal energy sources are locally available and environmentally friendly energy source in the case of reducing $\mathrm{CO}_{2}$ emission. The well-known application is for space heating and cooling in residential and commercial buildings with using GSHP system. Recently, various types of GHEs are used in the GSHP system to exchange heat with the ground. The heat exchange performance of the GHE is an important subject of GSHP system design.

Multiple-tube GHEs are studied to investigate the thermal interference and performance of multiple-tube ground heat exchangers (GHEs). Heat exchange rate of the multiple-tube GHEs are affected significantly by thermal interferences between the inlet and outlet tubes. Increasing the number of inlet tubes increases the contact surface area and then leads to increase of heat exchange with the ground. However, ineffective of heat exchange in the outlet tube caused by thermal interferences from the inlet tubes reduces the heat exchange rates for the GHEs. The GHE performances increase of $9.1 \%$ for three-tube, of $13.6 \%$ for four-tube, and of $20.1 \%$ for multi-tube compared with that of the U-tube. Thermal interferences between the pipes affect the GHE performance and should be considered in design of GHE.

\section{References}

[1] ASHRAE: 2011 ASHRAE Handbook: HVAC Applications, SI Edition, American Society of Heating, Refrigerating and Air-Conditioning Engineers, Inc., 1791 Tullie Circle, N.E., Atlanta, GA 30329.

[2] C. Yavuzturk, J.D. Spitler, , S.J. Rees, “A Transient Two-dimensional Finite Volume Model for the Simulation of Vertical U-tube Ground Heat Exchangers," ASHRAE Transactions, 1999, vol. 105(2), pp. 465-474.

[3] C. Yavuzturk, J.D. Spitler, "Field Validation of a Short Time-Step Model for Vertical Ground Loop Heat Exchangers," ASHRAE Transactions, 2001, vol. 107(1), pp. 617-625.

[4] V. Partenay, P. Riederer, T. Salquea, E. Wurtz, "The influence of the borehole short-time response on ground source heat pump system efficiency,” Energy and Buildings, 2011, vol. 43, pp. $1280-1287$.

[5] L. Lamarche, B. Beauchamp, "New solutions for the short-time analysis of geothermal vertical boreholes," International Journal of Heat and Mass Transfer, 2007, vol. 50, pp. 1408-1419. 
[6] G. Bandyopadhyay, W. Gosnold, M. Mann, "Analytical and semi-analytical solutions for short-time transient response of ground heat exchangers," Energy and Buildings, 2008, vol. 40, pp. 1816-1824.

[7] E.J. Kim, J.J. Roux, G. Rusaouen, F. Kuznik, "Numerical modelling of geothermal vertical heat exchangers for the short time analysis using the state model size reduction technique," Applied Thermal Engineering, 2010, vol. 30, pp. 706-714.

[8] A. Zarrella, M. Scarpa, M. De Carli, "Short time step analysis of vertical ground-coupled heat exchangers: The approach of CaRM," Renewable Energy, 2011, vol. 36, pp. 2357-2367.

[9] E. Zanchini, S. Lazzari, A. Priarone, "Long-term performance of large borehole heat exchanger fields with unbalanced seasonal loads and groundwater flow," Energy, 2012, vol. 38, pp. 66-77.

[10] P. Cui, H. Yang, Z. Fang, "Numerical analysis and experimental validation of heat transfer in ground heat exchangers in alternative operation modes," Energy and Buildings, 2008, vol. 40, pp. 1060-1066.

[11] H. Esen, M. Inalli, M. Esen, "Numerical and experimental analysis of a horizontal ground-coupled heat pump system," Building and Environment, 2007, vol. 42, pp. 1126-1134.

[12] H. Esen, M. Inalli, M. Esen, K. Pihtili, "Energy and exergy analysis of a ground-coupled heat pump system with two horizontal ground heat exchangers," Building and Environment, 2007, vol. 42, pp. 3606-3615.

[13] H. Esen, M. Inalli, "Thermal response of ground for different depths on vertical ground source heat pump system in Elazig, Turkey," Journal of the Energy Institute, 2009, vol. 82 (2), pp. 95-101.
[14] H. Esen, M. Inalli, Y. Esen, "Temperature distributions in boreholes of a vertical ground-coupled heat pump system," Renewable Energy, 2009, vol. 34, pp. 2672-2679.

[15] X. Li, Y. Chen, Z. Chen, J. Zhao, "Thermal performances of different types of underground heat exchangers," Energy and Buildings, vol. 38, pp. 543-547.

[16] Y. Hamada, H. Saitoh, M. Nakamura, H. Kubota, K. Ochifuji, "Field performance of an energy pile system for space heating," Energy and Buildings, 2007, vol. 39, pp. 517-524.

[17] J. Gao, X. Zhang, J. Liu, K.S. Li, J. Yang, "Thermal performance and ground temperature of vertical pile-foundation heat exchangers: A case study," Applied Thermal Engineering, 2008, vol. 28, pp. 2295-2304.

[18] C. Lee, M. Park, S. Min, S.H. Kang, B. Sohn, H. Choi, "Comparison of effective thermal conductivity in closed-loop vertical ground heat exchangers," Applied Thermal Engineering, 2011, vol. 31, pp. 3669-3676.

[19] L. Jun, Z. Xu, G. Jun, Y. Jie, "Evaluation of heat exchange rate of GHE in geothermal heat pump systems," Renewable Energy, 2009, vol. 34, pp. 2898-2904.

[20] Jalaluddin, A. Miyara, K. Tsubaki, S. Inoue, K. Yoshida, "Experimental study of several types of ground heat exchanger using a steel pile foundation," Renewable Energy, 2011, vol. 36, pp. 764-771.

[21] Jalaluddin, A. Miyara, "Thermal performance investigation of several types of vertical ground heat exchangers with different operation mode," Applied Thermal Engineering, 2012, vol. 33-34, pp. 167-174. 